\title{
Contextual tumor suppressor function of T cell death-associated gene 8 (TDAG8) in hematological malignancies
}

\author{
Calvin R. Justus' ${ }^{1}$ Edward J. Sanderlin ${ }^{1}$, Lixue Dong ${ }^{1}$, Tianai Sun ${ }^{4,5}$, Jen-Tsan Chi ${ }^{4,5}$, Kvin Lertpiriyapong ${ }^{3}$ \\ and Li V. Yang ${ }^{1,2^{*}}$ (1)
}

\begin{abstract}
Background: Extracellular acidosis is a condition found within the tumor microenvironment due to inadequate blood perfusion, hypoxia, and altered tumor cell metabolism. Acidosis has pleiotropic effects on malignant progression; therefore it is essential to understand how acidosis exerts its diverse effects. TDAG8 is a proton-sensing G-protein-coupled receptor that can be activated by extracellular acidosis.

Methods: TDAG8 gene expression was analyzed by bioinformatic analyses and quantitative RT-PCR in human hematological malignancies. Retroviral transduction was used to restore TDAG8 expression in U937, Ramos and other blood cancer cells. Multiple in vitro and in vivo tumorigenesis and metastasis assays were employed to evaluate the effects of TDAG8 expression on blood cancer progression. Western blotting, immunohistochemistry and biochemical approaches were applied to elucidate the underlying mechanisms associated with the TDAG8 receptor pathway.

Results: TDAG8 expression is significantly reduced in human blood cancers in comparison to normal blood cells. Severe acidosis, pH 6.4, inhibited U937 cancer cell proliferation while mild acidosis, pH 6.9, stimulated its proliferation. However, restoring TDAG8 gene expression modulated the U937 cell response to mild extracellular acidosis and physiological pH by reducing cell proliferation. Tumor xenograft experiments further revealed that restoring TDAG8 expression in U937 and Ramos cancer cells reduced tumor growth. It was also shown U937 cells with restored TDAG8 expression attached less to Matrigel, migrated slower toward a chemoattractant, and metastasized less in severe combined immunodeficient mice. These effects correlated with a reduction in c-myc oncogene expression. The mechanistic investigation indicated that Ga13/Rho signaling arbitrated the TDAG8-mediated c-myc oncogene repression in response to acidosis.
\end{abstract}

Conclusions: This study provides data to support the concept that TDAG8 functions as a contextual tumor suppressor down-regulated in hematological malignancies and potentiation of the TDAG8 receptor pathway may be explored as a potential anti-tumorigenic approach in blood cancers.

Keywords: TDAG8, GPR65, Acidosis, Tumor microenvironment, Hematological malignancies

\section{Background}

In the early twentieth century Otto Warburg recognized a metabolic phenomenon that occurred in cancer

\footnotetext{
*Correspondence: yangl@ecu.edu; liyang12@hotmail.com

1 Division of Hematology/Oncology, Department of Internal Medicine, Brody School of Medicine, East Carolina University, 600 Moye Blvd, Greenville, NC, USA

Full list of author information is available at the end of the article
}

cells, currently known as the Warburg effect [1-4]. Warburg discovered cancer cells favor glycolysis rather than oxidative phosphorylation for energy production, even in the presence of oxygen [1-4]. It was originally hypothesized that irreversible injury of mitochondrial respiration is the cause of cancer cell formation [1]. However, this hypothesis was to some extent discredited as most cancers retain their ability to exploit mitochondrial respiration, although to a lesser degree than 
normal cells [5-7]. As a result of unrestricted glycolysis the tumor microenvironment is spatially acidic [8-10]. Extracellular acidosis has pleiotropic effects on tumor growth and cancer progression [10-14]. Tumor acidosis can stimulate cell death, reduce cell proliferation, and induce chromosomal instability of normal somatic cells and cancer cells [13-16]. In addition, tumor cells that become resistant to extracellular acidosis have been reported more malignant and invasive [17, 18]. Therefore, extracellular tumor acidosis augments cancer progression in a Darwinian manner worsening disease prognosis. As such, it is imperative to understand how tumor cells sense and respond to acidic surroundings for adequate comprehension of cancer development.

T cell death-associated gene 8 (TDAG8, also known as GPR65) is a member of the proton sensing G-protein coupled receptor family, which also includes GPR4, GPR68 (OGR1), and GPR132 (G2A). The family of G-protein coupled receptors is activated by extracellular acidosis, which illuminates a receptor signaling connection to the acidic conditions found in tumor microenvironment [19]. The human TDAG8 gene has been mapped to chromosome 14q31-32.1, a location that abnormalities associated with $\mathrm{T}$ cell lymphoma and leukemia are found and is primarily expressed in immune cells and leukocyte-rich tissues such as circulating peripheral leukocytes, spleen, thymus, and tonsils $[20,21]$. TDAG8 has been reported to have both pro- and anti-oncogenic effects in blood cancers, which indicate TDAG8 effects are cell type and context dependent [22-24]. Therefore, it is imperative to understand the contextual effects of TDAG8 in hematological malignancies. Blood cancer cells are generally glycolytic and produce lactic acid that can acidify the microenvironment. Some types of hematological malignancies, such as lymphomas, have the ability to form solid tumors in which the tumor microenvironment is acidic. Other types of hematological malignancies, such as leukemia and multiple myeloma, form in and metastasize to bone marrow that has hypoxic and possibly acidic niches $[25,26]$. In rare cases, systemic lactic acidosis occurs in patients with hematological malignancies and is associated with poor prognosis [27].

In this study the effects of acidosis and TDAG8 gene expression was investigated in blood cancers. TDAG8 gene expression was examined in hematological malignancies revealing a significant reduction in comparison to normal immune cells and leukocyte-rich tissues. Functional studies demonstrated that restoration of TDAG8 gene expression suppressed the growth, migration and metastasis of blood cancer cells and sensitized them to extracellular acidosis.

\section{Methods}

\section{Bioinformatics}

TDAG8 gene expression was investigated in blood cancers using the Oncomine database. A differential analysis of TDAG8 gene expression was performed between leukemia, lymphoma, and myeloma datasets and normal immune cells and leukocyte-rich tissue. Additional bioinformatics analyses were performed on datasets from the National Center for Biotechnology Information (NCBI) Gene Expression Omnibus (GEO). The raw data was downloaded using expression console software HG_ u133_Plus_2 and HG_u133a_2 as libraries. The analysis was run and the RMA normalization method was used to generate the values graphed. The output file was then merged with the probe set downloaded from Affymetrix.

\section{Plasmid constructs}

The MSCV-huTDAG8-IRES-GFP construct was made previously and the empty construct, MSCV-IRES-GFP, was used as a control [23]. For the pMSCV-huTDAG8IRES-YFP-P2A-OF-LUC construct, the open reading frame of human TDAG8 was amplified using primers designed to contain the EcoRI and XhoI restriction enzyme sites: 5'-ATAAGAATGAA TTCACCATGAAC AGCACATGTATTGAAGAA- $3^{\prime}$ and 5'ATAAGAATG $^{\prime}$-ATA AATTCCTCGAG CTACTCAAGGACCTCTAATTCC AT-3'. The pMSCV-IRES-YFP-P2A-OF-LUC plasmid was then digested with EcoRI and XhoI and the huTDAG8 open reading frame was cloned into it generating the pMSCV-huTDAG8-IRES-YFP-P2A-OF-LUC construct. The resultant construct was verified by DNA sequencing.

\section{Cell lines and culture}

All the cancer cell lines were obtained from American Type Culture Collection (ATCC) with characterization as described in the product sheet. All cell lines were cultured in Roswell Park Memorial Institute medium (RPMI) supplemented with $10 \%$ fetal bovine serum (FBS) in a tissue culture incubator set at $37{ }^{\circ} \mathrm{C}$ and $5 \% \mathrm{CO}_{2}$. RPMI/FBS medium was buffered using $7.5 \mathrm{mM}$ HEPES, $7.5 \mathrm{mM}$ EPPS and $7.5 \mathrm{mM}$ MES, known collectively as RPMI/HEM, as previously described [23]. Cells used for experiments were $>95 \%$ viable as assessed by the trypan blue dye exclusion method.

To generate green fluorescent protein (GFP) and yellow fluorescent protein (YFP)/luciferase (Luc) cell lines with restored TDAG8 gene expression, retroviral-mediated cell transduction was performed as previously described [28]. To generate the Go13 signaling-deficient cell lines the p115 Rho RGS construct was subcloned into the pQCXIP vector as previously described $[28,29]$. The 
p115 Rho RGS-pQCXIP and empty pQCXIP retroviral vectors were then stably transduced into U937 cells.

\section{EdU cell proliferation assay}

The Click-iT ${ }^{\circledR}$ Plus EdU Imaging Kit (Thermo Fisher Scientific) was used to examine U937/Vector and U937/ TDAG8 cell proliferation. Fluorescence microscopy with the $\operatorname{EVOS}^{\circledR} f l$ Digital Inverted Microscope was used to take images of cells incorporating Hoescht ${ }^{\circledR} 33,342$ dye and the EdU analogue, and also images with transmitted light in the same field of view at a $200 \times$ magnification. Adobe Photoshop's counting tool was used to count the number of total cells according to Hoescht ${ }^{\circledR} 33,342$ dye and proliferating cells according to EdU positive cells.

\section{Cell growth competition assay}

The same number of non-GFP expressing cells (U937/ Parental or RPMI 8226/Parental) and GFP expressing cells (Vector or TDAG8) were mixed into a well and the percentages of non-GFP and GFP cells were measured using flow cytometry over 14 days. Cell population percentages were analyzed and graphed.

\section{Annexin V/7AAD staining}

Cells were stained with the PE Annexin V Apoptosis Detection Kit I (BD Biosciences). Emission of single cell fluorescence was measured at $572 \mathrm{~nm}$ for Annexin V, $647 \mathrm{~nm}$ for 7AAD, and $525 \mathrm{~nm}$ for GFP. The results were analyzed with CellQuest software (BD Biosciences).

\section{Quantitative reverse transcription-polymerase chain reaction (RT-PCR)}

Gene expression was determined by quantitative RT-PCR as previously described [23], using the following TaqMan predesigned primer/probes from Invitrogen, TDAG8 (Hs00269247_s1), c-myc (Hs00153408_m1), and $\beta$-actin (Hs99999903_m1). Relative gene expression was calculated using the $2^{-\Delta \Delta C t}$ method [30].

\section{Western blotting}

Western blot was performed as previously described [23]. Antibodies of c-myc (product \#5605), phospho-paxillin (Y118) (\#2541), phospho-CREB (S133) (\#9198), CREB (\#9197), caspase-3 (\#9665), caspase-9 (\#9502), cleaved PARP XP (\#5625), and $\beta$-actin (\#4970) were purchased from Cell Signaling Technology.

\section{Histology}

Immunohistochemistry (IHC) for antibodies against c-myc (Abcam, \#ab32072), cleaved PARP (Cell Signaling Technology, \#5625), Ki67 (Abcam, \#ab15580), and human nucleoli (Abcam, \#ab190710) was performed on paraffin-embedded $5 \mu \mathrm{m}$ sections. Antigen retrieval was performed by boiling slides in TRIS-EDTA $+0.1 \%$ Tween-20 pH 9.0 antigen retrieval buffer for 10-18 min. SuperPicture $^{\mathrm{TM}}$ 3rd Gen IHC Detection Kit (Invitrogen) was used to complete immunohistochemistry.

\section{Transwell cell migration assays}

Two hundred microliter of cells were seeded into the transwell insert at $5 \times 10^{6}$ cells $/ \mathrm{ml}$ in migration buffer consisting of RPMI media buffered to $\mathrm{pH} 7.4$ and $\mathrm{pH} 6.4$ without FBS and supplemented with $0.1 \%$ BSA. Chemoattractant $(5 \mathrm{ng} / \mathrm{mL}$ SDF1- $\alpha$ ) was then added into the bottom well. The plates were then incubated at $37{ }^{\circ} \mathrm{C}$ and $5 \% \mathrm{CO}_{2}$ for $5 \mathrm{~h}$. After $5 \mathrm{~h}$ the number of migrated cells was quantified using flow cytometry.

\section{Cell attachment assays}

Matrigel solution was added into each well to form a thin layer of gel. U937 cells were plated onto Matrigel and incubated at $37{ }^{\circ} \mathrm{C}$ and $5 \% \mathrm{CO}_{2}$ for $1 \mathrm{~h}$ in culture media buffered to $\mathrm{pH} 7.4$ or 6.4. After $1 \mathrm{~h}$ the media was aspirated and the wells were washed 4 times with RPMI to remove non-adherent cells. For the endothelial cell attachment assay Human Umbilical Vein Endothelial cells (HUVEC) were seeded on $0.1 \%$ gelatin-coated plates to create a monolayer. Next, U937 cells were plated in each well in culture media buffered to $\mathrm{pH} 7.4$ or 6.4. Plates were incubated at $37{ }^{\circ} \mathrm{C}$ and $5 \% \mathrm{CO}_{2}$ for $1 \mathrm{~h}$. After $1 \mathrm{~h}$ the media was aspirated and the wells were washed 4 times with RPMI. For all attachment assays several images were taken in various areas of the well to give an adequate representation. Cell attachment was quantified by counting every cell in each field of view.

\section{Primary tumor and metastasis xenograft}

NOD.CB17-Prkdc $<$ SCID $>/$ J mice were purchased from Jackson Laboratories and bred at East Carolina University animal facilities for research purposes. All experimental procedures were performed according to the NIH guide for the care and use of laboratory animals and the institutional regulations. In each experiment, $5 \times 10^{6} \mathrm{U} 937$ or Ramos cells were injected into the flanks of SCID mice. Tumor growth was measured daily using a caliper. Tail vein injections were performed with $2 \times 10^{6} \mathrm{U} 937$ cells in SCID mice. When mice reached endpoint parameters, e.g. lethargy, hunched posture, and unkempt appearance, they were euthanized for analysis. The experiment was terminated 8 months after injection when the remaining mice showed no signs of disease progression. To monitor U937-Luc tumor growth in vivo, intraperitoneal injection with D-Luciferin (Caliper Life Sciences, Catalogue \# 119222) at $15 \mathrm{mg} / \mathrm{ml}$ in DPBS was performed. Subsequently, mice were imaged using the IVIS Lumina XR unit. 


\section{Statistical analysis}

Statistical analysis was performed using the GraphPad Prism software. The unpaired $t$ test was used to test for statistical significance between 2 groups. Error bars represent \pm standard error (SEM) in all graphs. ns: $\mathrm{P}>0.05$, ${ }^{*} \mathrm{P}<0.05$, ${ }^{* * *} \mathrm{P}<0.01,{ }^{* * * *} \mathrm{P}<0.001$.

\section{Results}

TDAG8 gene expression is reduced significantly in hematologic malignancies in comparison to normal immune cells and leukocyte-rich tissue

Oncomine bioinformatics analysis identified that TDAG8 gene expression was reduced in multiple forms of blood cancer, including acute myeloid leukemia (AML) (2.2 and 6.1-fold) [31, 32], chronic lymphocytic leukemia (CLL) (3.3-, 1.7-, 2.3-, and 2.6-fold) (Table 1) [31, 33-35], T-cell acute lymphoblastic leukemia (TCALL) (3.1-fold), B-cell childhood acute lymphoblastic leukemia (BCCALL) (2.5-fold), B-cell acute lymphoblastic leukemia (BALL) (2.4-fold), pro B-cell acute lymphoblastic leukemia (PBALL) (1.3-fold), hairy cell leukemia $(\mathrm{HCl})$ (1.9-fold), and T-cell prolymphocytic leukemia (TCPLL) (3.9-fold) (Table 1) [31, 33, 36]. In addition, TDAG8 gene expression is reduced in several lymphomas such as diffuse large B-cell lymphoma
(DLBCL) (1.4- and 1.9-fold) [33, 34], follicular lymphoma (FL) (1.4- and 2.0-fold) [33, 34], pleural effusion lymphoma (PEL) (2.7-fold) [33], and Burkitt lymphoma (BL) (1.8-fold) [33] (Table 1). Lastly, TDAG8 expression was found reduced in smoldering myeloma (SM) (2.6-fold) (Table 1) [37]. The search in the Oncomine Research Premium Edition also revealed various cancer cell lines that were resistant to chemotherapeutics had reduced TDAG8 gene expression in comparison to cancer cell lines that were sensitive to those particular chemotherapeutics (Table 2) [38, 39]. A separate analyses of datasets from NCBI GEO revealed that TDAG8 gene expression is significantly reduced 4.5-fold in AML (GEO Series ID GSE9476), 2.9-fold in CLL (GEO Series ID GSE22529), 3.6-fold in TCPLL with inv(14)(q11q32) (GEO Series ID GSE5788), 2.7-fold in chronic B-cell lymphocytic leukemia (CBLL) (GSE26725), 3.0-fold in DLBCL (GEO series ID GSE12195), and 2.8-fold in FL (GEO series ID GSE12195) (Fig. 1a-e). The same pattern was found in various blood cancer cell lines. For example, TDAG8 gene expression was reduced 45-fold in U937 cells, 8-fold in Ramos cells, undetectable in RPMI 8226 cells, 625-fold in K562 cells, and 3-fold in Jurkat cells in comparison to normal peripheral blood leukocytes (Fig. 2a).

Table 1 TDAG8 gene expression is reduced significantly in blood cancers

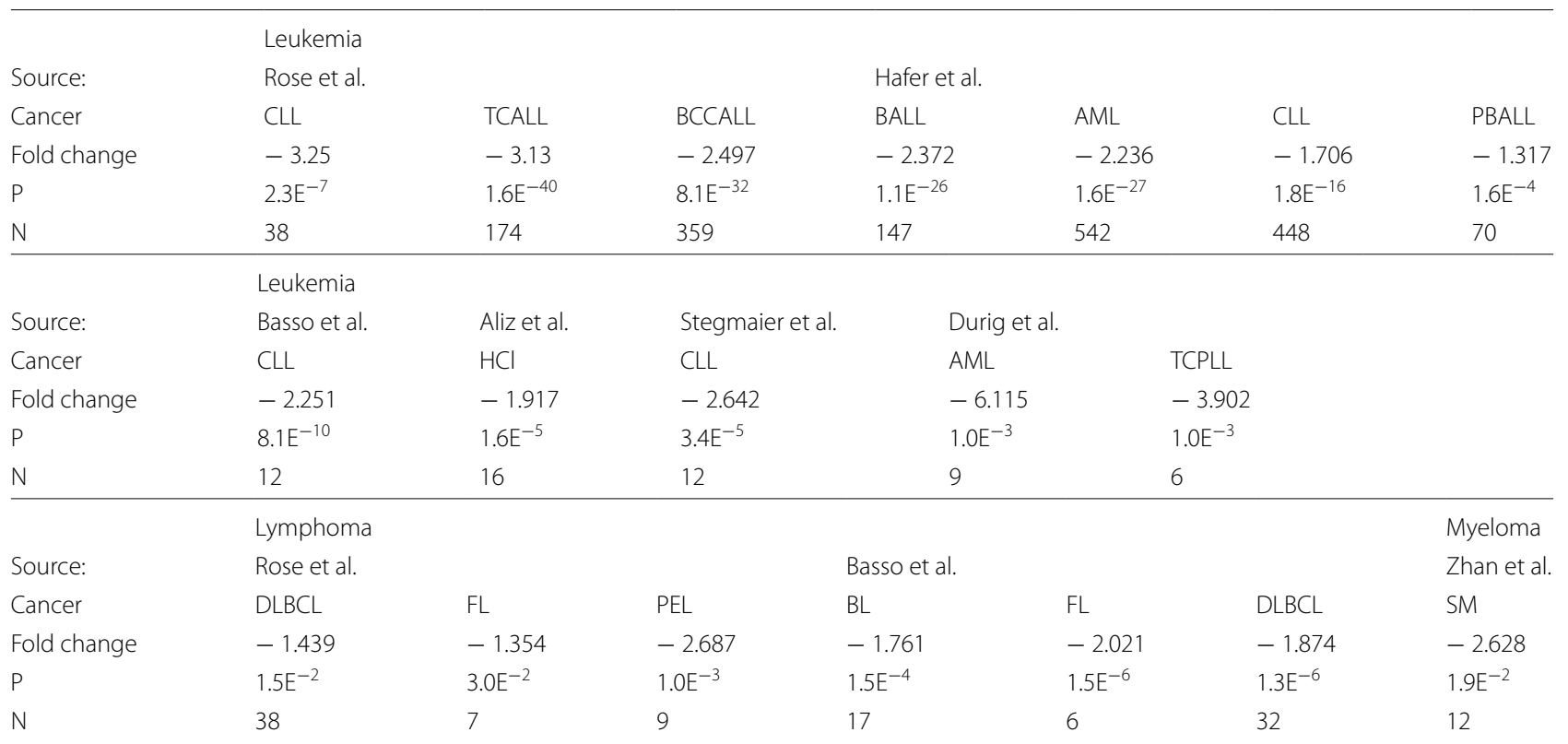

CLL chronic lymphocytic leukemia, TCALL T-cell acute lymphoblastic leukemia, BCCALL B-cell childhood acute lymphoblastic leukemia, BALL B-cell acute lymphoblastic leukemia, $A M L$ acute myeloid leukemia, PBALL pro B-cell acute lymphoblastic leukemia, $H C l$ hairy cell leukemia, TCPLL T-cell prolymphocytic leukemia. TDAG8 gene expression is also reduced significantly in $D L B C L$ diffuse large B-cell lymphoma, $F L$ follicular lymphoma, $P E L$ pleural effusion lymphoma, $B L$ Burkitt's lymphoma, SM smoldering myeloma. Rose et al. normal blood cell control: B-lymphocyte (4), CD4+ T-lymphocyte (5), germinal center B-lymphocyte (1), umbilical cord blood B-lymphocyte (1), umbilical cord blood T-lymphocyte (1). Hafer et al. normal blood cell control: peripheral blood mononuclear cell (74). Basso et al. normal blood cell control: B-lymphocyte (5), centroblast (5), memory B-lymphocyte (5), naive pre-germinal center B-lymphocyte (5), small cleaved follicle center cell (5). Aliz et al. normal blood cell control: B-lymphocyte (16), CD4+ T-lymphocyte (6), centroblast (1), germinal center B-lymphocyte (2), lymph node (1), memory B-lymphocyte (3), tonsil (1). Stegmaier et al. normal blood cell control: monocyte (3), neutrophil (3). Durig et al. normal blood cell control: CD3+ peripheral blood cell (8). Zhan et al. normal blood cell control: bone marrow (22) 
Table 2 Reduced TDAG8 gene expression correlates with resistance to various chemotherapeutics

\begin{tabular}{|c|c|c|c|c|c|c|}
\hline Drug & $\begin{array}{l}\text { Elesclomol } \\
\text { (leukemia) }\end{array}$ & $\begin{array}{l}\text { Panobinostat } \\
\text { (multi-cancer) }\end{array}$ & $\begin{array}{l}\text { Irinotecan } \\
\text { (multi-cancer) }\end{array}$ & $\begin{array}{l}\text { Topotecan } \\
\text { (multi-cancer) }\end{array}$ & $\begin{array}{l}\text { Navitoclax } \\
\text { (leukemia) }\end{array}$ & MK2206 (leukemia) \\
\hline $\begin{array}{l}\text { Mechanism of } \\
\text { action }\end{array}$ & $\begin{array}{l}\text { Unknown oxidative } \\
\text { Stress }\end{array}$ & $\begin{array}{l}\text { Histone deacety- } \\
\text { lase inhibitor }\end{array}$ & $\begin{array}{l}\text { Topoisomerase } \\
\text { inhibitor }\end{array}$ & $\begin{array}{l}\text { Topoisomerase } \\
\text { inhibitor }\end{array}$ & $\begin{array}{c}\mathrm{BCl}-2, \mathrm{BCl}-\mathrm{XL} \text {, and } \\
\text { BCl-w inhibitor }\end{array}$ & AKT inhibitor \\
\hline $\begin{array}{l}\text { Resistant cell lines } \\
(\mathrm{Rn})\end{array}$ & 21 & 164 & 84 & 124 & 12 & 17 \\
\hline $\begin{array}{l}\text { Sensitive cell lines } \\
(\text { Sn) }\end{array}$ & 4 & 86 & 71 & 154 & 6 & 3 \\
\hline $\begin{array}{l}\text { TDAG8 gene } \\
\text { expression of } S n \\
\text { vs Rn }\end{array}$ & +2.3 & +2.7 & +3.2 & +2.2 & +2.4 & +3.8 \\
\hline$P$ & $4.8 \mathrm{E}^{-2}$ & $2.6 \mathrm{E}^{-7}$ & $4.2 \mathrm{E}^{-8}$ & $2.9 \mathrm{E}^{-10}$ & $3.4 \mathrm{E}^{-2}$ & $7.8 \mathrm{E}^{-4}$ \\
\hline
\end{tabular}

Cancer cells of various origins categorized as resistant to specific chemotherapeutics demonstrate a significant reduction in TDAG8 gene expression. The expression of TDAG8 in 4 cell lines sensitive to elesclomol is 2.3 -fold higher than in 21 cell lines resistant. The expression of TDAG8 in 86 cell lines categorized as sensitive to panobinostat is 2.7-fold higher than in 164 cell lines categorized as resistant. The expression of TDAG8 in 71 cell lines categorized as sensitive to irinotecan is 3.2 -fold higher than in 84 cell lines categorized as resistant. The expression of TDAG8 in 154 cell lines categorized as sensitive to topotecan is 2.2 -fold higher than in 124 cell lines categorized as resistant. The expression of TDAG 8 in 6 cell lines categorized as sensitive to navitoclax is 2.4 -fold higher than in 12 cell lines categorized as resistant. The expression of TDAG8 in 3 cell lines categorized as sensitive to MK2206 is 3.8-fold higher than in 17 cell lines categorized as resistant

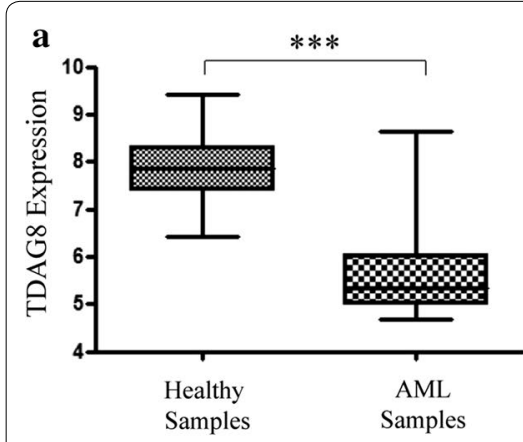

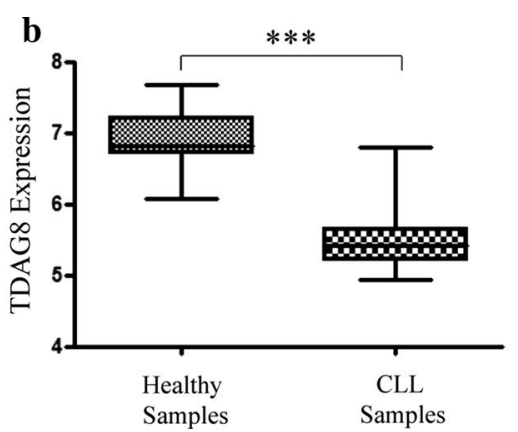

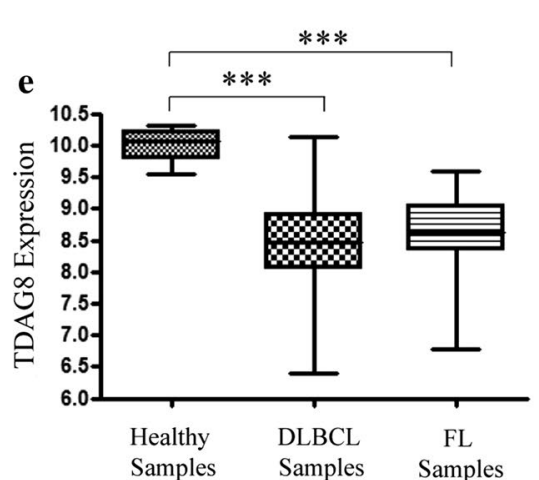

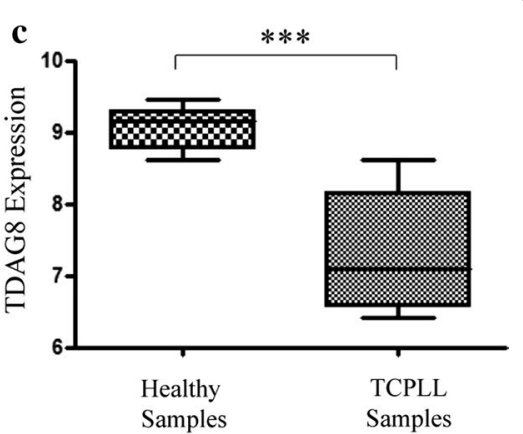

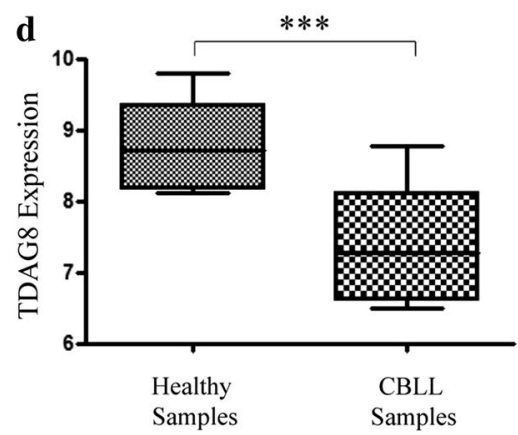

Fig. 1 TDAG8 gene expression is reduced in patients with blood cancers in comparison to healthy donor's immune cells or leukocyte-rich tissue. a The expression of TDAG8 is reduced 4.5-fold in CD34+ bone marrow and CD34+ peripheral blood cells isolated from patients with AML ( $N=20$ ) in comparison to CD34+ bone marrow and CD34+ peripheral blood cells isolated from healthy donors $(N=26)$. $\mathbf{b}$ The expression of TDAG8 is reduced 2.9-fold in CD19+/CD5+ peripheral blood mononuclear cells isolated from patients with CLL $(\mathrm{N}=11)$ in comparison to CD19+/CD5+ peripheral blood mononuclear cells isolated from healthy donors $(N=39)$. c The expression of TDAG8 is reduced 3.6-fold CD3+ peripheral blood cells $(\mathrm{N}=8)$ isolated from patients with TCPLL in comparison to CD3+ peripheral blood cells isolated from healthy donors $(N=6)$. $\mathbf{d}$ The expression of TDAG8 is reduced 2.7-fold in CD19+ peripheral blood lymphocytes isolated from patients with CBLL $(N=6)$ in comparison to CD19+ peripheral blood lymphocytes isolated from healthy donors $(\mathrm{N}=11)$. e The expression of TDAG8 is reduced by 3.0-fold in DLBCL biopsy samples $(\mathrm{N}=73)$ in comparison to B-lymphocytes isolated from healthy donors $(\mathrm{N}=9)$. The expression of TDAG8 is also reduced by 2.8-fold in human FL biopsy samples $(N=38)$ in comparison to B-lymphocytes isolated from healthy donors $(N=9)$. AML acute myeloid leukemia, $C L L$ chronic lymphocytic leukemia, DLBCL diffuse large B-cell lymphoma, FL follicular lymphoma, TCPLL T-cell prolymphocytic leukemia with inv(14)(q11q32), CBLL chronic B-cell lymphocytic leukemia. Y-axis is $\log _{2}$ scale. ${ }^{* *} \mathrm{P}<0.001$ 


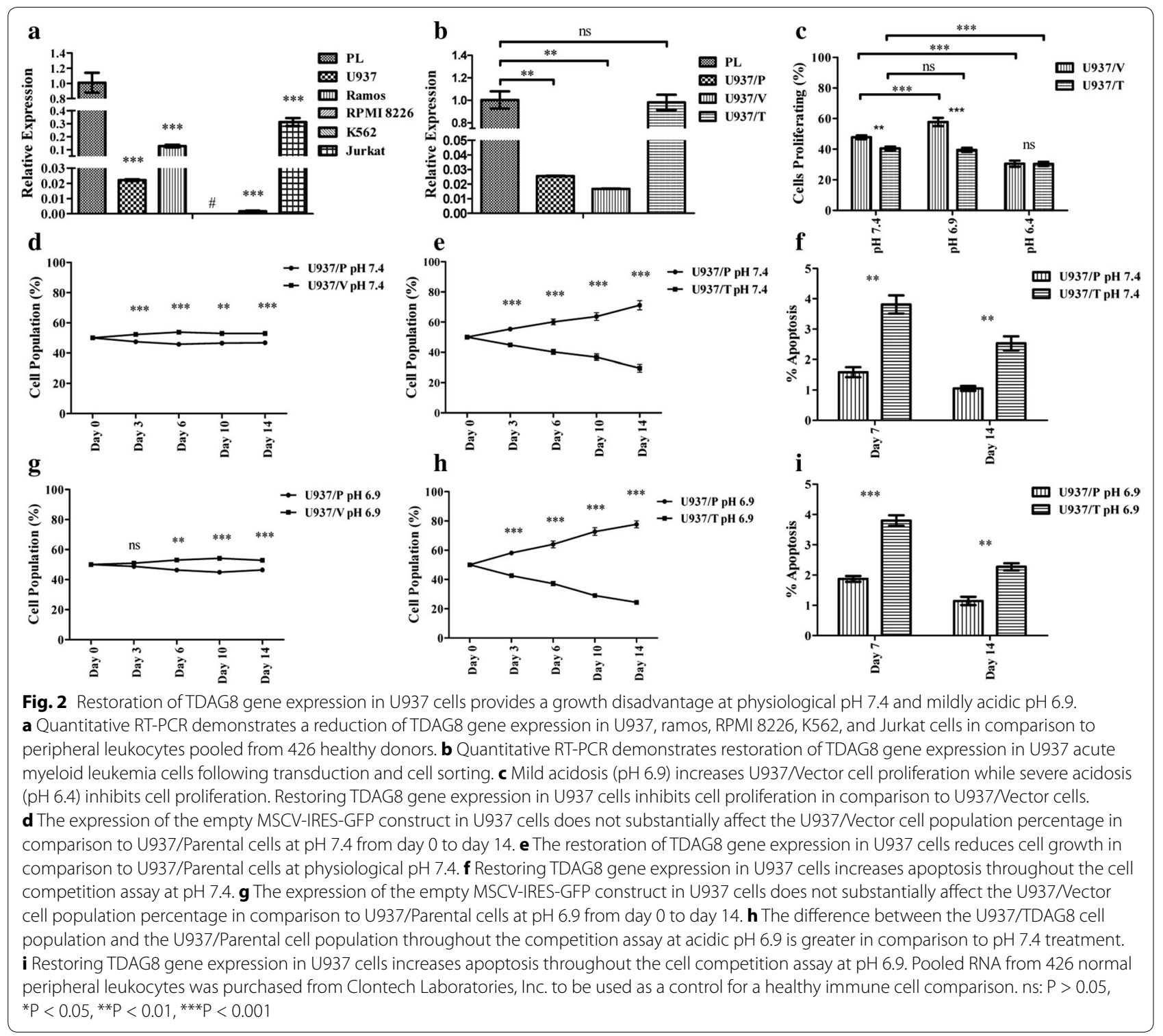

TDAG8 gene expression provides a disadvantage to blood cancer cell growth

As TDAG8 gene expression is commonly downregulated in hematological malignancies (Tables 1, 2 and Fig. 1), we investigated its function by restoring TDAG8 expression in blood cancer cell lines such as U937, Ramos and RPMI 8226 with low TDAG8 expression. The U937 cell line was originally established from a patient with histiocytic lymphoma and later found to possess characteristics of acute myeloid leukemia (AML) cells [40]. U937 cells were used as a model system for this study because the cells have features of both lymphoma and leukemia. Proliferation of U937 cells transduced with a construct containing the human TDAG8 gene (U937/TDAG8) was compared to
U937 cells transduced with an empty vector (U937/Vector). The expression level of TDAG8 mRNA in U937/ TDAG8 cells was restored to the similar level as that in normal leukocytes (Fig. 2b). Due to the lack of a reliable TDAG8 antibody, we were unable to detect TDAG8 protein expression. Instead, we examined the TDAG8 downstream signaling activities and found the phosphorylation of CREB was higher in U937/TDAG8 cells than that in U937/Vector cells (Additional file 1: Figure S1A), suggesting that restoration of TDAG8 expression augments its downstream $G$ protein signaling. Similarly, CREB phosphorylation was increased in Ramos/TDAG8 cells with the restoration of TDAG8 expression (Additional file 1: Figure S1B, C). 
In comparison to U937/Vector cells, U937/TDAG8 cells proliferated $7 \%$ less $(47.8 \%$ vs. $40.5 \%$ proliferating cells) at physiological pH 7.4 (Fig. 2c). When U937/ Vector cells were treated with $\mathrm{pH} 6.9$, there was a $10 \%$ increase in cell proliferation in comparison to physiological $\mathrm{pH}$ 7.4. However, restoring TDAG8 gene expression sensitized U937 cells to media buffered to $\mathrm{pH} 6.9$ and suppressed cell proliferation at pH 6.9 (Fig. 2c). Severe acidosis, $\mathrm{pH}$ 6.4, significantly reduced cell proliferation in both U937/Vector and U937/TDAG8 cells (Fig. 2c).

Next, cell growth competition assays were performed to demonstrate negative selection of U937 cells expressing the TDAG8 gene. In the cell growth competition assay there was a slight change in the U937/ParentalU937/Vector cell populations $(50 \pm 5 \%)$ after 14 days (Fig. 2d). However, the U937/TDAG8 cell population was only $30 \%$ of the total population of cells in comparison to $70 \%$ of the U937/Parental cells at $\mathrm{pH} 7.4$ (Fig. 2e). Quantitative RT-PCR also demonstrated that restoration of TDAG8 expression in U937/TDAG8 cells reduced the expression of c-myc oncogene on day 0 and day 14 of the competition assay in comparison to the U937/Vector cells (Additional file 1: Figure S2A, B). The growth competition assay was also performed in medium buffered to mildly acidic $\mathrm{pH}$ 6.9. The U937/ TDAG8 cell population was significantly reduced to $23 \%$ of the total population of cells at pH 6.9 (Fig. 2h). The U937/Vector and U937/Parental cells showed slight changes $(50 \pm 5 \%)$ relative to each other at $\mathrm{pH}$ 6.9 (Fig. 2g). Results were similar when the competition assay was performed with the RPMI 8226/Vector and RPMI 8226/TDAG8 myeloma cells (Additional file 1: Figure S3).

The GFP mean fluorescence value remained stable from day 0 to day 14 with little variation in the U937/ Vector cells when co-cultured with the U937/Parental cells (Additional file 1: Figure S2C). However, U937/ TDAG8 cell GFP mean fluorescence value as an indicator of TDAG8 transgene expression was considerably reduced (Additional file 1: Figure $\mathrm{S} 2 \mathrm{C}$ ). When comparing day 0 with day 14 at $\mathrm{pH} 6.9$ there was a $65 \%$ reduction in GFP mean fluorescence value of U937/TDAG8 cells (Additional file 1: Figure S2D).

Annexin V PE/7AAD staining was performed at day 7 and day 14 of the competition assay to examine U937 cell apoptosis. It was determined there was a significant increase of apoptosis in U937/TDAG8 cells in comparison to U937/Parental cells at $\mathrm{pH} 7.4$ and at $\mathrm{pH} 6.9$ (Fig. 2f, i). Increased apoptosis of U937/TDAG8 cells also correlated with an increase in caspase 3, caspase 9, and PARP cleavage (Additional file 1: Figure S4).

\section{Restoration of TDAG8 gene expression reduces primary} tumor growth in severe combined immunodeficient (SCID) mice

U937 cells were originally isolated from a patient with histiocytic lymphoma and can form solid tumors, which are known to be spatially acidic. To determine the effects of restoring TDAG8 gene expression on U937 primary tumor growth, subcutaneous xenograft experiments were performed in SCID mice. A significant inhibition of U937/TDAG8 tumor growth was observed throughout the experiments (Fig. 3a). In addition, overall tumor mass was reduced by $\sim 50 \%$ in U937/TDAG8 tumors (Fig. 3b). Similar trends were found following Ramos/Vector and Ramos/TDAG8 lymphoma cell injections into SCID mice (Additional file 1: Figure S5). In vivo luminescence imaging was also used to visualize tumor growth over 2 weeks. The pattern previously observed in U937/TDAG8 cells, i.e. reduced tumor growth, was consistent with the U937/ TDAG8-Luc cells expressing TDAG8 and the luciferase marker gene (Fig. 3c).

\section{Decreased c-myc expression is detected in the tumor zone close to necrotic regions}

Immunohistochemistry (IHC) of c-myc expression revealed that sections nearest necrotic regions of tumors, known to be acidic [17], had reduced expression of c-myc (Fig. $3 \mathrm{~d}-\mathrm{i}$ ). The areas that were investigated for low c-myc expression were negative for cleaved PARP indicating that intact cells nearest necrotic regions were viable (Fig. 3e, g). In addition, it was also revealed that invasive cancer cells in the tumor peripheral regions had increased expression of c-myc and $\mathrm{Ki}-67$ and were negative for cleaved PARP (Fig. 3g-i).

\section{Acidosis/TDAG8 reduces c-myc expression through Ga13/ Rho signaling}

IHC analysis of c-myc protein expression revealed that U937/TDAG8 tumor cells expressed lower levels of c-myc in comparison to U937/Vector control (Fig. 4a, b). It was also qualitatively determined that c-myc expression was undetectable in numerous U937/TDAG8 cells in the tumor (Fig. 4b). In comparison, the majority of U937/ Vector cells expressed c-myc at a high level (Fig. 4a). It was also determined that restoring TDAG8 gene expression reduces c-myc protein expression significantly in comparison to the U937/Vector control cells at physiological pH 7.4 in vitro (Fig. 4c, d). In addition, activation of TDAG8 by extracellular acidification, representing similar conditions as the tumor microenvironment, further reduces c-myc expression in comparison to $\mathrm{pH} 7.4$ treatment and to the U937/Vector controls (Fig. 4c, d). These observations are consistent with previous studies 


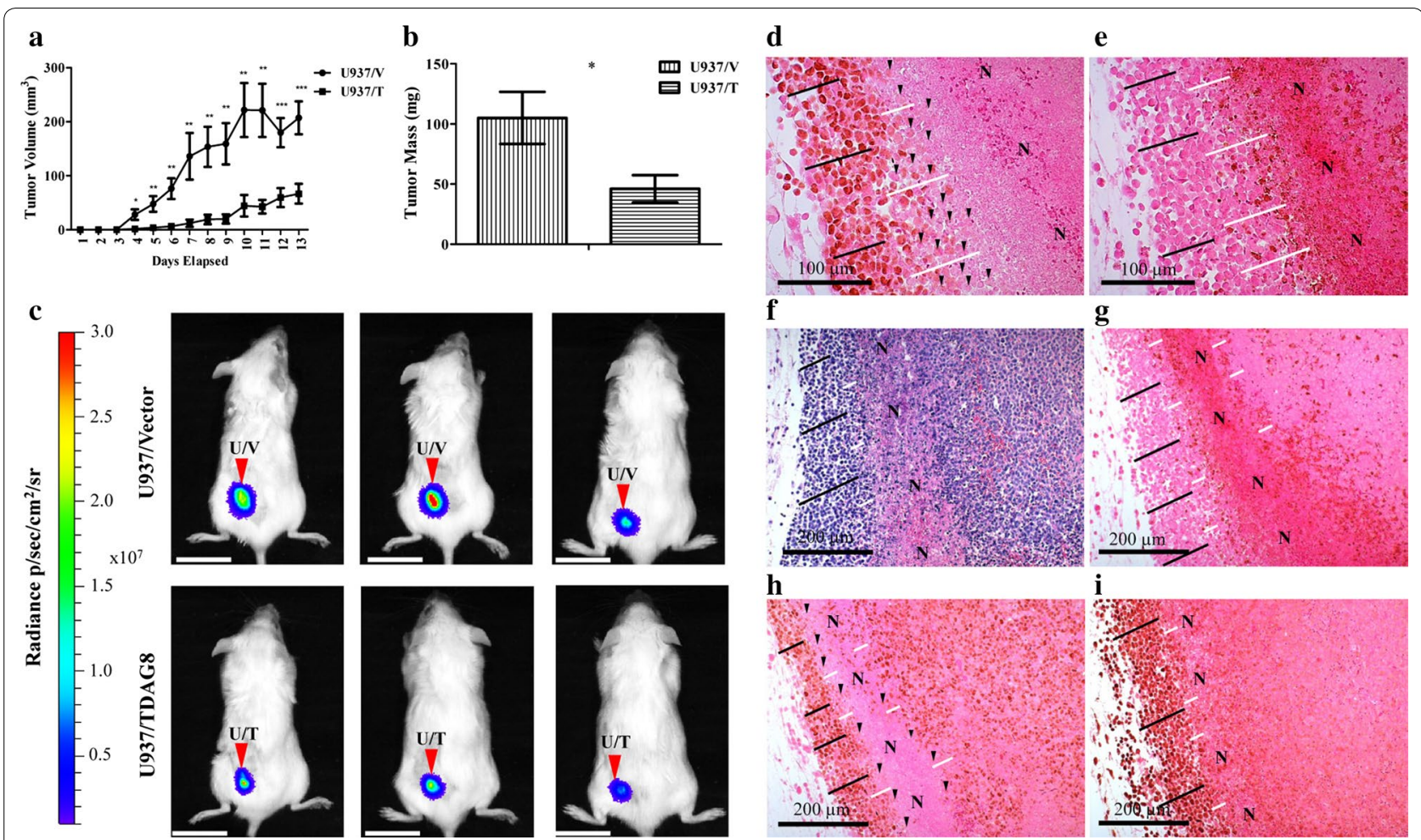

Fig. 3 Restoring TDAG8 gene expression in U937 cells reduces primary tumor growth in SCID mice. a U937/TDAG8 tumor growth was significantly reduced in comparison to U937/Nector tumors from day 4 to necropsy $(N=14)$. b U937/TDAG8 tumor mass was reduced significantly in comparison to U937/Nector tumors following necropsy. $\mathbf{c}$ In vivo imaging of 3 mice injected with U937/Nector-Luc or U937/TDAG8-Luc cells 6 days after injection. Scale Bar $=2 \mathrm{~cm}$. d, e Immunohistochemistry of c-myc $\mathbf{d}$ and cleaved PARP $\mathbf{e}$ in U937Nector tumors demonstrating regions nearest necrotic areas display reduced c-myc oncogene expression while still live. f-i Hematoxylin and eosin staining (f) and immunohistochemistry of U937Nector tumors demonstrating invasive peripheral regions of U937 tumors display increased proliferation by c-myc (h) and Ki67 (i) while demonstrating less apoptosis, cleaved PARP $(\mathbf{g})$. N necrotic. White lines indicate areas adjacent to necrotic zones. Black lines indicate tumor cells that are invasive correlating with higher c-myc and Ki67 expression. Black arrowheads indicate single tumor cells that demonstrate reduced or no c-myc expression. ${ }^{* P}<0.05,{ }^{* *} P<0.01,{ }^{* * *} P<0.001$

showing that TDAG8 has some constitutive activities at the physiological $\mathrm{pH}$ and is fully activated under acidic $\mathrm{pH}[41]$.

Following inhibition of Ga13 signaling by the p115 RGS construct $[28,29]$, Western blot analysis determined that c-myc expression was restored in the U937/TDAG8 cells after treatment with media buffered to $\mathrm{pH} 7.4$ and $\mathrm{pH}$ 6.4 (Fig. 4e, f). These results reveal that Go13 signaling is central for TDAG8-mediated c-myc inhibition at physiological $\mathrm{pH} 7.4$ and acidic $\mathrm{pH}$ 6.4. The activation of Rho GTPases with CN01, downstream from the p115-RGS Ga13 inhibition, reduced the expression of c-myc, indicating that Go13/Rho signaling in U937 cells inhibits c-myc expression (Fig. 4e, f). Similar results were found for caspase 3, caspase 9, and PARP cleavage fol-

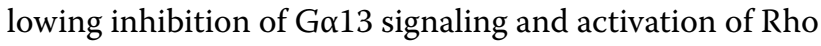
(Additional file 1: Figure S6). Therefore, the data suggests TDAG8 exerts its growth inhibitory effects through acti-

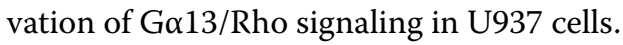

Restoration of TDAG8 gene expression in U937 cells reduces cell attachment and migration correlating with altered focal adhesion dynamics

Restoration of TDAG8 gene expression reduced the ability for U937 cells to attach to Matrigel at physiological pH 7.4 by more than $50 \%$ (Fig. 5a). Activation of TDAG8 by extracellular acidosis reduced U937 cell attachment even further demonstrating the anti-metastatic capabilities of TDAG8 (Fig. 5a). U937 cell attachment to a HUVEC monolayer was also investigated revealing a reduction in U937/TDAG8 cell attachment to endothelial cells at physiological pH 7.4 and acidic pH 6.4 (Additional file 1: Figure S7A). However, overall cell attachment to a HUVEC monolayer was increased at acidic $\mathrm{pH} 6.4$ likely due to the effects of acidosis on endothelial cell-mediated attachment [42]. It was also determined that U937/TDAG8-Luc cells exhibited less cell migration towards the chemoattractant SDF-1 $\alpha$ in comparison to U937/Vector-Luc cells (Fig. 5b). In addition, treatment with $\mathrm{pH} 6.4$ further 


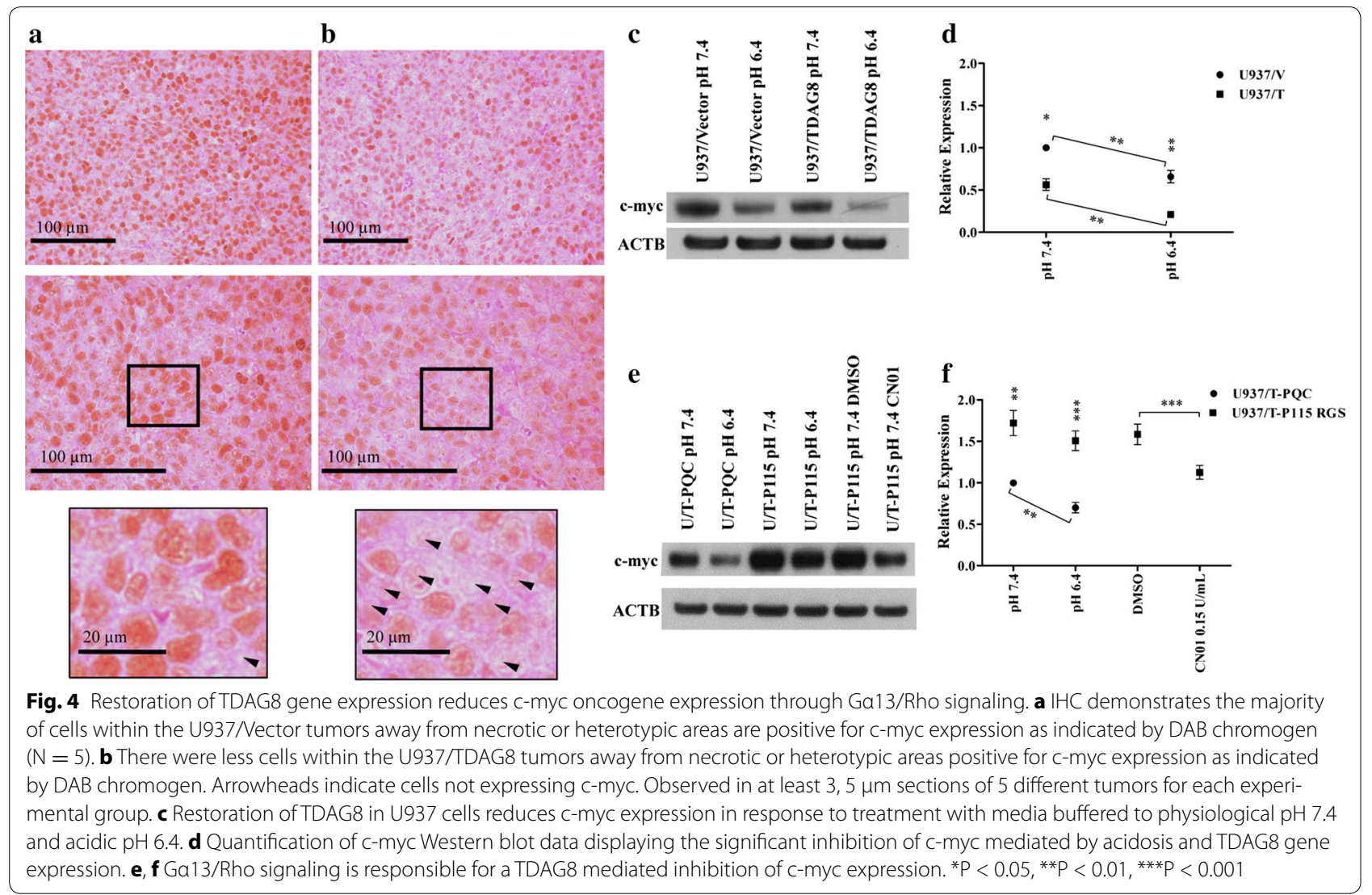

$\mathbf{a}$

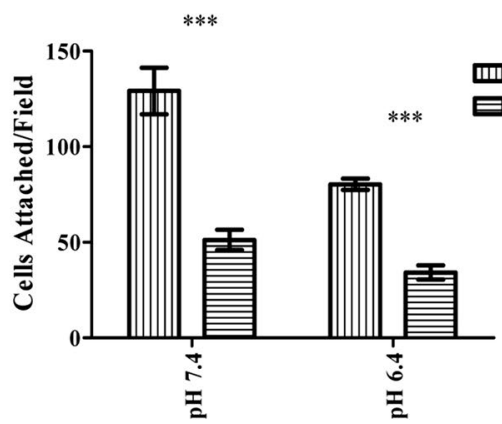

c

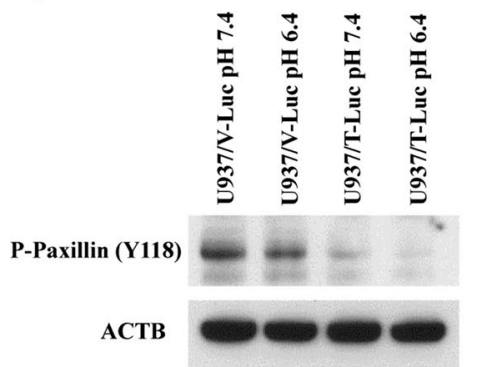

b

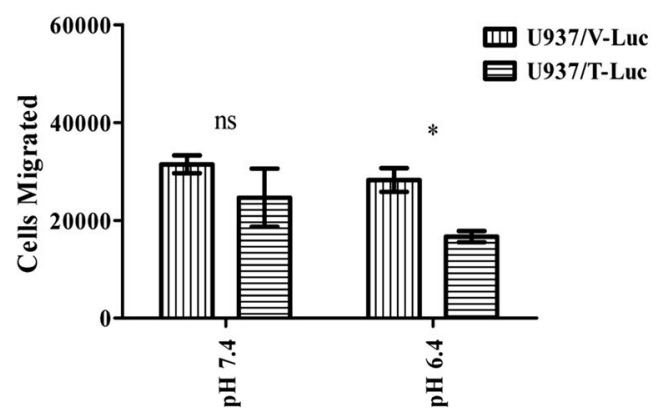

d

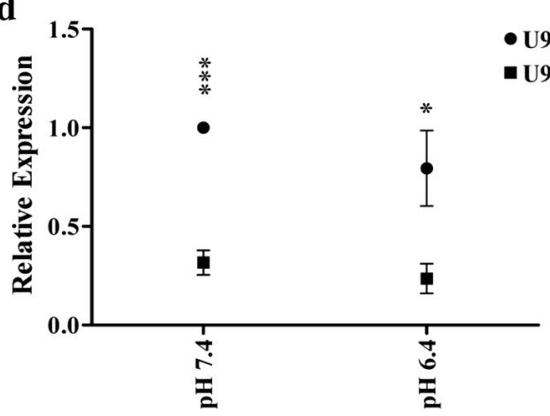

Fig. 5 TDAG8 gene expression reduces U937 cell attachment and migration. a Restoration of TDAG8 gene expression inhibits U937 cell attachment to matrigel. $\mathbf{b} \cup 937$ cell migration towards SDF1-a is inhibited by TDAG8 gene expression at pH 7.4 and pH 6.4. c Acidosis and restoration of TDAG8 gene expression reduces phosphorylation of paxillin at $Y 118$ in U937 cells. d Quantification of paxillin phosphorylation at Y118 reveals a significant reduction in U937/TDAG8-luc cells at $\mathrm{pH} 7.4$ and 6.4. ns: $P>0.05$, ${ }^{*} P<0.05, P<0.01$, ${ }^{* * *} P<0.001$ 
reduced the migration of U937/TDAG8-Luc cells in comparison to the U937/Vector-Luc cells (Fig. 5b). This was also observed in the U937 cells that were transduced with the GFP construct (Additional file 1: Figure S7B).

Increased activity of focal adhesion proteins such as focal adhesion kinase (FAK) and paxillin have been correlated with poor patient survival and increased malignancy of blood and other cancers [43-48]. We found that restoring TDAG8 gene expression in U937 cells significantly inhibited the phosphorylation of paxillin Y118 at $\mathrm{pH} 7.4$ and $\mathrm{pH} 6.4$ (Fig. 5c, d), suggesting a reduced activity of the FAK/paxillin pathway $[49,50]$. In addition, when treated with media buffered to $\mathrm{pH} 6.4$ the phosphorylation of paxillin Y118 was reduced in comparison to the $\mathrm{pH} 7.4$ treatment groups (Fig. $5 \mathrm{c}, \mathrm{d}$ ).

\section{Restoration of TDAG8 gene expression in U937 cells reduces metastasis in SCID mice following tail vein injections}

Overall, the in vivo imaging of SCID mice was not sensitive enough to visualize micro-metastasis of tumor cells (Fig. 6a-e). However, larger nodules and tumors were easily visualized (Fig. 6a). Metastasis of U937/Vector cells to the lymph node, bone of the limb, and other organs in SCID mice was detected by IVIS luminescence imaging (Fig. 6a; Additional file 1: Figure S7C). To further quantify metastasis, the mouse lungs were analyzed using an anti-human nucleoli antibody specific for human cells (Fig. 6b-e). The results indicate the severity of U937 cell metastasis to the lung of SCID mice was significantly reduced by restoring TDAG8 expression (Fig. 6f).

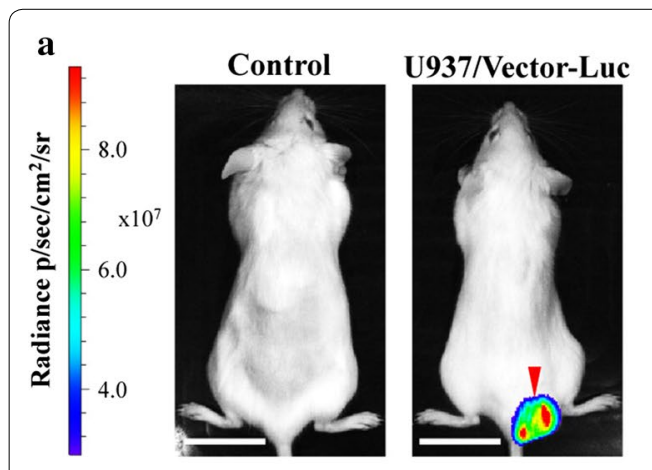

f

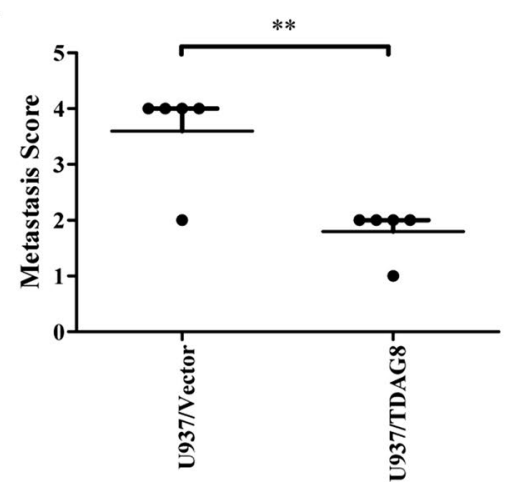

b

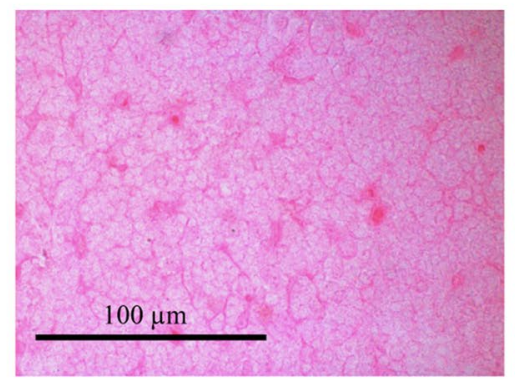

d

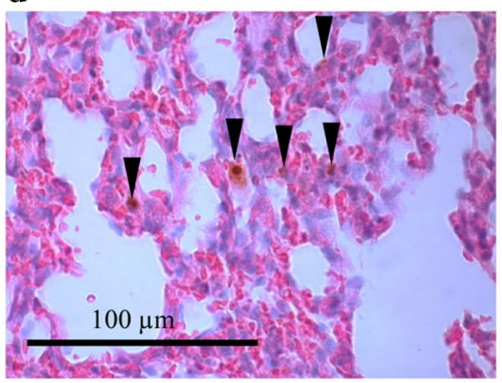

c

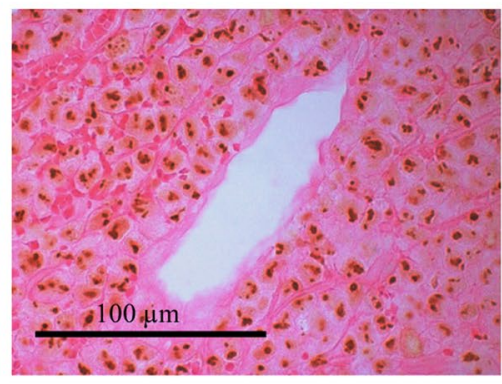

e

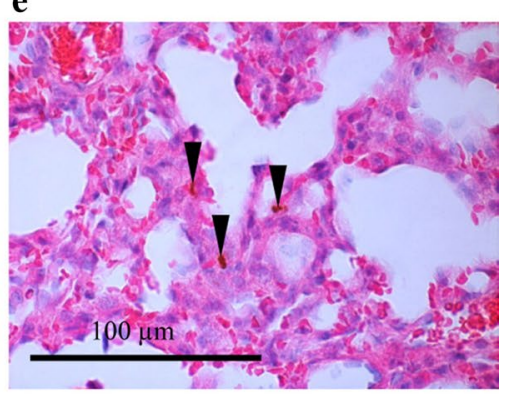

Fig. 6 Restoration of TDAG8 gene expression reduces U937 cell metastasis in SCID mice. In vivo luminescence imaging identified larger tumors but was not sensitive enough to identify micro metastasis in SCID mice. a IVIS luminescence imaging. Scale bar $=2 \mathrm{~cm}$. b Normal mouse spleen section with negative staining demonstrating the specificity of the anti-human nucleoli antibody. c Tumor metastasis in the lymph node was positive for human nucleoli. d, e Hematoxylin and eosin staining and IHC of the human nucleoli antibody was used to identify nuclear localization of the antibody signals of U937Nector tumor cells in the lung of SCID mice. $\mathbf{f}$ Analysis of SCID mice lungs following IHC of human nucleoli reveals a significant reduction in metastasis. Mice with no metastasis detected were given a score of 0 . Mice with $<2$ average metastatic lesions in each $5 \mu \mathrm{m}$ section of the lung were given a score of 1, from 2 to 5 average metastatic lesions were given a score of 2, from 6 to 10 average metastatic lesions were given a score of 3 , and from 11 or more average metastatic lesions were given a score of 4 . In addition, lesions that were larger than 20 cells or large enough to see with the IVIS Lumina XR unit was given a 4. For each experimental group injected with either U937/Nector-Luc or U937/TDAG8-Luc cells the individual scores were added up and averaged to give a metastasis score. The scoring system consisted of analyzing a total of 6 sections of lung for each mouse injected. Every section was separated by at least $20 \mu \mathrm{m}$ of tissue to give representative sections of various areas of the lung. ${ }^{* *} \mathrm{P}<0.01$ 


\section{Discussion}

The effect of extracellular acidosis on cancer progression is complex; therefore it is important to understand the cancer cell biological response to it [13]. In this study it was determined that diverse extremities of extracellular acidosis had differential effects on cellular proliferation (Fig. 2c-e, g, h). It was clearly demonstrated that mild extracellular acidosis, $\mathrm{pH}$ 6.9, increased U937 cell proliferation while severe acidosis, $\mathrm{pH}$ 6.4, repressed it (Fig. 2c). In addition, this report evaluated the effects of tumor acidosis on c-myc oncogene expression in vivo. In tumor sections nearest necrotic regions, known to be acidic [17], c-myc oncogene expression was reduced significantly in live tumor cells (Fig. 3d-i). However, invasive cancer cells that were invading new tissue, devoid of blood vessels and nutrients, did not follow this pattern (Fig. 3d-i). Conversely, invasive tumor cells had increased expression of c-myc and Ki-67 signifying they are actively proliferating and invasive despite extracellular acidosis and nutrient deprivation (Fig. $3 \mathrm{~d}-\mathrm{i}$ ). The discovered pattern of tumor cell invasiveness in harsh extracellular conditions concurrently associating with increased cell proliferative markers is similar to an acid resistant phenotype described previously $[17,18]$. Importantly, understanding that extracellular acidosis reduces c-myc oncogene expression in some tumor cells while not in others provides an original understanding for the heterotypic and spatial tumor cell response to extracellular acidosis. To understand how tumor cells sense extracellular acidosis the proton sensing G-protein coupled receptor TDAG8 was investigated.

The data provided in this study indicates that TDAG8 gene expression is suppressive for U937 cell malignancy. It was discovered that TDAG8 gene expression is reduced in the majority of blood cancers in comparison to normal immune cells or leukocyte-rich tissue (Table 1 and Fig. 1). In addition, higher expression of the TDAG8 gene correlates with increased sensitivity toward various chemotherapeutics (Table 2). Using U937 acute myeloid leukemia cells as a model system TDAG8 gene expression was restored to a normal physiological level to test the hypothesis that TDAG8 gene expression provides a disadvantage for blood cancer cell malignancy. Restoring TDAG8 gene expression in U937 cells reduced cell proliferation in vitro and tumor growth and metastasis in vivo (Figs. 2, 3, 6). The ability for TDAG8 gene expression to provide a disadvantage for U937 cell proliferation, tumor growth, and metastasis confirmed that TDAG8 gene expression provides a disadvantage for blood cancer progression. Similar tumor suppressive functions of TDAG8 were observed in other blood cancer cells such as Ramos Burkitt lymphoma and RPMI 8226 multiple myeloma cells (Additional file 1: Figures S3 and S5).
Moreover, TDAG8's inherent ability to reduce c-myc expression at physiological $\mathrm{pH} 7.4$ and acidic $\mathrm{pH} 6.4$ is central (Fig. 4a-c) [23]. This is consistent with previous results demonstrating that TDAG8 exhibits constitutive activity at physiological $\mathrm{pH}$ and is further activated at acidic $\mathrm{pH}$ [41]. Moreover, the results from this report indicate that the inhibitory effects of acidosis on c-myc oncogene expression are partially due to TDAG8-mediated $\mathrm{G \alpha} 13 /$ Rho signaling (Fig. 4e-f). This idea aligns

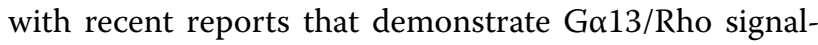
ing suppresses oncogenesis and acts as a tumor suppressor in lymphoma [51-53]. Overall, it is hypothesized in this report that extracellular acidosis provides a selective pressure against cancer cells, which modulates clonal cell evolution. Moreover, TDAG8 is a proton sensor that plays an important role in this process, which has important implications for blood cancer progression as well as cancer cell clonal evolution parallel to extracellular acidosis found within the tumor microenvironment.

TDAG8 has been reported to have a diverse repertoire of pro- and anti-oncogenic effects that are cancer type and context dependent [22-24, 54-57]. These seemingly conflicting observations can potentially be explained by TDAG8 downstream signaling-the Go13 G-protein/

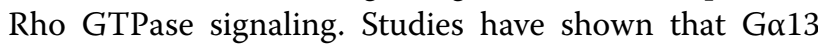
and Rho GTPases can have pro-oncogenic or antioncogenic effects in a cancer type and context dependent manner [51-53, 58-61]. Ga13 and Rho GTPases exhibit pro-tumorigenic effects in various types of epithelial cancers [58-60], but have anti-tumorigenic effects in hematological malignancies [51-53]. The differential effects of Go13/Rho GTPases may contribute to the antioncogenic effects of TDAG8 in hematological malignancies and the pro-oncogenic effects in other cancer types [22-24, 54-57]. To better understand the involvement of TDAG8 in various tumor types, we performed additional bioinformatic analyses of the Oncomine database to evaluate TDAG8 (GPR65) expression in cancerous and normal tissues [62-69]. The results show that TDAG8 is over-expressed in several types of epithelial tumors, including brain tumor, kidney cancer, and head and neck cancer when compared to their normal tissue counterparts (Additional file 2: Table S1). Methodologically, however, cautions should be taken when interpreting the expression profile of TDAG8 in epithelial tumors. RNA for gene expression analysis was isolated from whole tumor tissues [62-69]. As a result, it is unclear whether the over-expression of TDAG8 is derived from epithelial cancer cells or from infiltrated leukocytes which are known to highly express TDAG8 [20, 21, 70, 71]. Also, interestingly, TDAG8 expression is either not changed [54] or down-regulated in lung cancer samples when compared to normal lung tissues (Additional file 2: Table 
S1). Taken together, the expression pattern of TDAG8 in epithelial tumors varies, probably complicated by infiltrated leukocytes that highly express TDAG8 [20, 21, 70, 71]. In contrast, TDAG8 expression is consistently downregulated in hematological malignancies when compared to normal blood cells and tissues (Table 1 and Fig. 1). Moreover, functional results from this study, together with previous studies [22, 23], suggest that TDAG8 acts as a contextual tumor suppressor in hematological malignancies.

\section{Conclusions}

In summary, this study reveals that the acid-sensing receptor TDAG8 (GPR65) is down-regulated in multiple types of hematological malignancies, including leukemia, lymphoma and multiple myeloma. Our in vitro and in vivo results demonstrate that TDAG8 functions as a tumor suppressor in hematological malignancies and sensitizes blood cancer cells to acidotic stress in the microenvironment. Mechanistically, the TDAG8mediated Ga13/Rho signaling results in the reduction of c-myc oncogene expression which may contribute to TDAG8 tumor suppressive effects. This observation is also concordant with the tumor suppressor function of Ga13/Rho in hematological malignancies [51-53]. Our findings in this study suggest that potentiation of the TDAG8 (GPR65) receptor pathway may be exploited as a potential therapeutic approach for the treatment of hematological malignancies.

\section{Additional files}

Additional file 1: Figure S1. Restoration of TDAG8 gene expression results in increased phosphorylation of CREB at serine 133 in U937 and Ramos cells. (A) Restoration of TDAG8 gene expression in U937 cells results in stimulation of CREB phosphorylation at serine 133 indicating the TDAG8 activity level is increased. (B) TDAG8 gene expression is restored in Ramos cells to a level that is physiologically relevant. (C) Restoration of TDAG8 gene expression in Ramos cells results in stimulation of CREB phosphorylation at serine 133 indicating the TDAG8 activity level is increased. ${ }^{*} P<0.01$. Figure S2. TDAG8 gene expression restoration reduces c-myc oncogene expression in U937 cells. (A, B) Restoration of TDAG8 gene expression reduces c-myc oncogene expression at the mRNA level in U937 cells. (C) Over 14 days U937/TDAG8 GFP expression is reduced at physiological $\mathrm{pH} 7.4$ while U937Nector GFP is stable. (D) Reduction of U937/TDAG8 GFP expression is further augmented by activation of TDAG8 with acidic $\mathrm{pH} 6.9$ treatment while the U937/Nector GFP is stable. ns: $P>0.05,{ }^{*} P<0.05,{ }^{* * * P}<0.001$. Figure $\mathbf{S 3}$. Restoration of TDAG8 gene expression in RPMI 8226 myeloma cells inhibits cell proliferation. (A) The empty vector does not substantially affect RPMI 8226 cell proliferation at physiological pH 7.4 in comparison to the RPMI 8226 parental cells. (B) Restoration of TDAG8 gene expression significantly reduces RPMI 8226 cell proliferation at physiological pH 7.4 in comparison to the RPMI 8226 parental cells. (C) The empty vector does not substantially affect RPMI 8226 cell proliferation at acidic $\mathrm{pH} 6.9$ in comparison to the RPMI 8226 parental cells. (D) Restoration of TDAG8 gene expression significantly reduces RPMI 8226 cell growth at acidic $\mathrm{pH} 6.9$ in comparison to the RPMI 8226 parental cells. ${ }^{* * *}>0.001$. Figure S4. Restoration of TDAG8 gene expression increases apoptosis signaling. (A, B) Restoration of TDAG8 gene expression stimulates cleaved caspase 3 in U937 cells at physiological pH 7.4 and acidic pH 6.4. (A and C) Restoration of TDAG8 gene expression increases cleaved caspase 9 in U937 cells at physiological pH 7.4. (A and D) Restoration of TDAG8 gene expression increases cleaved PARP in U937 cells at acidic $p H$ 6.4. ns: $P>0.05,{ }^{*} P<0.05$. Figure S5. Restoration of TDAG8 gene expression in Ramos lymphoma cells reduces primary tumor growth in SCID mice. (A) Representative image of a mouse subcutaneously injected with Ramos/Nector (left flank) and Ramos/TDAG8 (right flank) cells. (B) Restoration of TDAG8 in Ramos cells significantly delays primary tumor growth in SCID mice starting day 9 after injection. (C) Restoring TDAG8 gene expression in Ramos cells moderately reduces overall tumor mass after necropsy on day 21. (D) Representative image of Ramos/Vector and Ramos/TDAG8 tumors excised from SCID mice. ns: $P>0.05,{ }^{*} P<0.05,{ }^{* * P}<0.01,{ }^{* * * P}<0.001$. Figure S6. TDAG8 stimulates apoptotic signaling through Ga13/Rho signaling. (A, B) Inhibition of Ga13 signaling in U937/TDAG8 cells reduces cleaved caspase 3 and activation of Rho in U937/TDAG8 cells stimulates cleaved caspase 3. (A and C) Inhibition of Ga13 signaling in U937/TDAG8 cells reduces cleaved caspase 9 and activation of Rho in U937/TDAG8 cells stimulates cleaved caspase 9. (A and D) Inhibition of Ga13 signaling in U937/TDAG8 cells reduces cleaved PARP and activation of Rho in U937/TDAG8 cells stimulates cleaved PARP. ns: $P>0.05$, *P $<0.05$. Figure S7. Restoration of TDAG8 gene expression in U937 cells reduces attachment to a HUVEC monolayer and reduces migration toward a chemoattractant. (A) Restoration of TDAG8 gene expression reduces overall U937 cell attachment to a HUVEC monolayer while extracellular acidosis increases cell attachment. (B) Restoration of TDAG8 gene expression significantly reduces U937 cell migration toward a chemoattractant (SDF-1a) while extracellular acidosis reduces overall U937 cell migration. (C) In vivo imaging of a SCID mouse injected with U937/Nector-Luc cells that presented with hind limb paralysis and metastasis throughout the body. ${ }^{*} \mathrm{P}<0.05$, ${ }^{*} \mathrm{P}<0.01$, ${ }^{* *} \mathrm{P}<0.001$.

Additional file 2: Table S1. TDAG8 gene expression in various cancer types compared to normal tissues.

\section{Abbreviations}

GPCR: G protein coupled receptor; Ga13: G protein alpha 13; pH: potential of hydrogen; RGS: regulator of G protein signaling; Rho: rho GTPase; RT-PCR: reverse transcription-polymerase chain reaction; SCID: severe combined immunodeficient; TDAG8: T cell death associated gene 8 .

\section{Authors' contributions}

CRJ and LVY conceptualized and designed the study; CRJ, EJS, LD, and KL performed the experiments; LVY supervised the study; CRJ, EJS, and LVY analyzed the data; TS and JTC performed the GEO microarray dataset analysis; CRJ wrote the first draft of the manuscript; LVY critically revised the manuscript. All authors read and approved the final manuscript.

\section{Author details}

${ }^{1}$ Division of Hematology/Oncology, Department of Internal Medicine, Brody School of Medicine, East Carolina University, 600 Moye Blvd, Greenville, NC, USA. ${ }^{2}$ Department of Anatomy and Cell Biology, Brody School of Medicine, East Carolina University, Greenville, NC 27834, USA. ${ }^{3}$ Department of Comparative Medicine, Brody School of Medicine, East Carolina University, Greenville, NC, USA. ${ }^{4}$ Department of Molecular Genetics and Microbiology, Duke University, Durham, NC, USA. ${ }^{5}$ Center for Genomic and Computational Biology, Duke University, Durham, NC, USA.

\section{Acknowledgements}

We thank Dr. Owen Witte for providing the luciferase construct, Dr. Douglas Weidner for providing assistance on flow cytometry, and Dr. Zhigang Li for technical assistance at the initial stage of the project.

\section{Competing interests}

The authors declare that they have no competing interests.

\section{Availability of data and materials}

All data generated during the study are included in the article and its additional information files. 


\section{Consent for publication}

Not applicable.

\section{Ethics approval and consent to participate}

The animal study protocol was approved by the Institutional Animal Care and Use Committee (IACUC) of East Carolina University.

\section{Funding}

This study was supported in part by research grants from the Vidant Cancer Research and Education Fund (to LVY), the Coach Rock Roggeman Cancer Research Fund (to LVY), and the East Carolina University Research and Creative Activity Award (to LVY). The research in Dr. Li Yang's lab was also partly supported by the NIH Grant R15DK109484. The funding bodies had no role in the design of the study, collection, analysis and interpretation of data, or in writing the manuscript.

\section{Publisher's Note}

Springer Nature remains neutral with regard to jurisdictional claims in published maps and institutional affiliations.

Received: 4 August 2017 Accepted: 30 September 2017

Published online: 10 October 2017

\section{References}

1. Warburg O. On the origin of cancer cells. Science. 1956;123:309-14.

2. Vander Heiden MG, Cantley LC, Thompson CB. Understanding the Warburg effect: the metabolic requirements of cell proliferation. Science. 2009;324:1029-33.

3. Warburg O. On respiratory impairment in cancer cells. Science. 1956;124:269-70

4. Warburg O, Wind F, Negelein E. The metabolism of tumors in the body. J General Physiol. 1927;8:519-30.

5. Newsholme EA, Crabtree B, Ardawi MSM. The role of high rates of glycolysis and glutamine utilization in rapidly dividing cells. Biosci Rep. 1985:5:393-400.

6. Koppenol WH, Bounds PL, Dang CV. Otto Warburg's contributions to current concepts of cancer metabolism. Nat Rev Cancer. 2011;11:325-37.

7. Kroemer G. Mitochondria in cancer. Oncogene. 2006;25:4630-2

8. Vaupel P. Physiological properties of malignant tumours. NMR Biomed. 1992;5:220-5

9. Vaupel P, Kallinowski F, Okunieff P. Blood flow, oxygen and nutrient supply, and metabolic microenvironment of human tumors: a review. Cancer Res. 1989;49:6449-65.

10. Gatenby RA, Smallbone K, Maini PK, Rose F, Averill J, Nagle RB, Worrall L, Gillies RJ. Cellular adaptations to hypoxia and acidosis during somatic evolution of breast cancer. Br J Cancer. 2007:97:646-53.

11. Ibrahim-Hashim A, Cornnell HH, Abrahams D, Lloyd M, Bui M, Gillies RJ, Gatenby RA. Systemic buffers inhibit carcinogenesis in TRAMP mice. J Urol. 2012:188:624-31.

12. Fukumura D, Xu L, Chen Y, Gohongi T, Seed B, Jain RK. Hypoxia and acidosis independently up-regulate vascular endothelial growth factor transcription in brain tumors in vivo. Cancer Res. 2001;61:6020-4.

13. Justus $C R$, Dong L, Yang LV. Acidic tumor microenvironment and $\mathrm{pH}$ sensing G protein-coupled receptors. Front Physiol. 2013;4:354.

14. Justus CR, Sanderlin EJ, Yang LV. Molecular connections between cancer cell metabolism and the tumor microenvironment. Int J Mol Sci. 2015;16:11055-86.

15. Morita T, Nagaki T, Fukuda I, Okumura K. Clastogenicity of low pH to various cultured mammalian cells. Mutat Res. 1992:268:297-305.

16. Gatenby RA, Gawlinski ET, Gmitro AF, Kaylor B, Gillies RJ. Acidmediated tumor invasion: a multidisciplinary study. Cancer Res. 2006:66:5216-23.

17. Damaghi M, Tafreshi NK, Lloyd MC, Sprung R, Estrella V, Wojtkowiak JW, Morse DL, Koomen JM, Bui MM, Gatenby RA, Gillies RJ. Chronic acidosis in the tumour microenvironment selects for overexpression of LAMP2 in the plasma membrane. Nat Commun. 2015:6:8752.
18. Damaghi M, Gillies R. Phenotypic changes of acid adapted cancer cells push them toward aggressiveness in their evolution in the tumor microenvironment. Cell Cycle. 2016;16:0.

19. Ishii S, Kihara Y, Shimizu T. Identification of T cell death-associated gene 8 (TDAG8) as a novel acid sensing G-protein-coupled receptor. J Biol Chem. 2005;280:9083-7.

20. Choi JW, Lee SY, Choi Y. Identification of a putative G protein-coupled receptor induced during activation-induced apoptosis of T cells. Cell Immunol. 1996;168:78-84

21. Kyaw H, Zeng Z, Su K, Fan P, Shell BK, Carter KC, Li Y. Cloning, characterization, and mapping of human homolog of mouse T-cell death-associated gene. DNA Cell Biol. 1998;17:493-500.

22. Malone MH, Wang Z, Distelhorst CW. The glucocorticoid-induced gene TDAG8 encodes a pro-apoptotic G protein-coupled receptor whose activation promotes glucocorticoid-induced apoptosis. J Biol Chem. 2004:279:52850-9.

23. Li Z, Dong L, Dean E, Yang LV. Acidosis decreases C-Myc oncogene expression in human lymphoma cells: a role for the proton-sensing $G$ protein-coupled receptor TDAG8. Int J Mol Sci. 2013;14:20236-55.

24. Ryder C, McColl K, Zhong F, Distelhorst CW. Acidosis promotes BCl-2 family-mediated evasion of apoptosis: involvement of acid-sensing G protein-coupled receptor Gpr65 signaling to Mek/Erk. J Biol Chem. 2012;287:27863-75

25. Hu J, Van Valckenborgh E, Menu E, De Bruyne E, Vanderkerken K. Understanding the hypoxic niche of multiple myeloma: therapeutic implications and contributions of mouse models. Dis Model Mech. 2012;5:763-71.

26. Spencer JA, Ferraro F, Roussakis E, Klein A, Wu J, Runnels JM, Zaher W, Mortensen $\sqcup$, Alt C, Turcotte R, et al. Direct measurement of local oxygen concentration in the bone marrow of live animals. Nature. 2014:508:269-73.

27. Ruiz JP, Singh AK, Hart P. Type B lactic acidosis secondary to malignancy: case report, review of published cases, insights into pathogenesis, and prospects for therapy. Sci World J. 2011;11:1316-24.

28. Yang LV, Radu CG, Wang L, Riedinger M, Witte ON. Gi-independent macrophage chemotaxis to lysophosphatidylcholine via the immunoregulatory GPCR G2A. Blood. 2005;105:1127-34.

29. Kozasa T, Jiang X, Hart MJ, Sternweis PM, Singer WD, Gilman AG, Bollag G, Sternweis PC. p1 15 RhoGEF, a GTPase activating protein for Galpha12 and Galpha13. Science. 1998;280:2109-11.

30. Livak KJ, Schmittgen TD. Analysis of relative gene expression data using real-time quantitative PCR and the 2(-Delta Delta C(T)) method. Methods. 2001;25:402-8.

31. Haferlach T, Kohlmann A, Wieczorek L, Basso G, Kronnie GT, Bene MC, De Vos J, Hernandez JM, Hofmann WK, Mills Kl, et al. Clinical utility of microarray-based gene expression profiling in the diagnosis and subclassification of leukemia: report from the international microarray innovations in leukemia study group. J Clin Oncol. 2010;28:2529-37.

32. Stegmaier K, Ross KN, Colavito SA, O'Malley S, Stockwell BR, Golub TR. Gene expression-based high-throughput screening (GE-HTS) and application to leukemia differentiation. Nat Genet. 2004:36:257-63.

33. Basso K, Margolin AA, Stolovitzky G, Klein U, Dalla-Favera R, Califano A. Reverse engineering of regulatory networks in human B cells. Nat Genet. 2005;37:382-90.

34. Rosenwald A, Alizadeh AA, Widhopf G, Simon R, Davis RE, Yu X, Yang L, Pickeral OK, Rassenti LZ, Powell J, et al. Relation of gene expression phenotype to immunoglobulin mutation genotype in B cell chronic lymphocytic leukemia. J Exp Med. 2001;194:1639-47.

35. Alizadeh AA, Eisen MB, Davis RE, Ma C, Lossos IS, Rosenwald A, Boldrick JC, Sabet H, Tran T, Yu X, et al. Distinct types of diffuse large B-cell lymphoma identified by gene expression profiling. Nature. 2000;403:503-11.

36. Durig J, Bug S, Klein-Hitpass L, Boes T, Jons T, Martin-Subero Jl, Harder L, Baudis M, Duhrsen U, Siebert R. Combined single nucleotide polymorphism-based genomic mapping and global gene expression profiling identifies novel chromosomal imbalances, mechanisms and candidate genes important in the pathogenesis of T-cell prolymphocytic leukemia with inv(14)(q11q32). Leukemia. 2007;21:2153-63.

37. Zhan F, Barlogie B, Arzoumanian V, Huang Y, Williams DR, Hollmig K, Pineda-Roman M, Tricot G, van Rhee F, Zangari M, et al. Gene-expression signature of benign monoclonal gammopathy evident in multiple myeloma is linked to good prognosis. Blood. 2007;109:1692-700. 
38. Garnett MJ, Edelman EJ, Heidorn SJ, Greenman CD, Dastur A, Lau KW, Greninger P, Thompson IR, Luo X, Soares J, et al. Systematic identification of genomic markers of drug sensitivity in cancer cells. Nature. 2012;483:570-5

39. Barretina J, Caponigro G, Stransky N, Venkatesan K, Margolin AA, Kim S, Wilson CJ, Lehar J, Kryukov GV, Sonkin D, et al. The cancer cell line encyclopedia enables predictive modelling of anticancer drug sensitivity. Nature. 2012;483:603-7.

40. Zhang W, Konopleva M, Ruvolo VR, McQueen T, Evans RL, Bornmann WG, McCubrey J, Cortes J, Andreeff M. Sorafenib induces apoptosis of AML cells via Bim-mediated activation of the intrinsic apoptotic pathway. Leukemia. 2008;22:808-18.

41. Radu CG, Nijagal A, McLaughlin J, Wang L, Witte ON. Differential proton sensitivity of related $G$ protein-coupled receptors $T$ cell death-associated gene 8 and G2A expressed in immune cells. Proc Natl Acad Sci USA. 2005;102:1632-7.

42. Chen A, Dong L, Leffler NR, Asch AS, Witte ON, Yang LV. Activation of GPR4 by acidosis increases endothelial cell adhesion through the CAMP/ Epac pathway. PLoS ONE. 2011;6:e27586.

43. Jagadeeswaran $R$, Surawska H, Krishnaswamy S, Janamanchi V, Mackinnon AC, Seiwert TY, Loganathan S, Kanteti R, Reichman T, Nallasura V, et al. Paxillin is a target for somatic mutations in lung cancer: implications for cell growth and invasion. Cancer Res. 2008;68:132-42.

44. Despeaux M, Chicanne G, Rouer E, De Toni-Costes F, Bertrand J, MansatDe Mas V, Vergnolle N, Eaves C, Payrastre B, Girault JA, Racaud-Sultan C. Focal adhesion kinase splice variants maintain primitive acute myeloid leukemia cells through altered Wnt signaling. Stem Cells. 2012;30:1597-610.

45. Sood AK, Coffin JE, Schneider GB, Fletcher MS, DeYoung BR, Gruman LM, Gershenson DM, Schaller MD, Hendrix MJ. Biological significance of focal adhesion kinase in ovarian cancer: role in migration and invasion. Am J Pathol. 2004;165:1087-95.

46. Chen DL, Wang ZQ, Ren C, Zeng ZL, Wang DS, Luo HY, Wang F, Qiu MZ, Bai L, Zhang DS, et al. Abnormal expression of paxillin correlates with tumor progression and poor survival in patients with gastric cancer. J Transl Med. 2013;11:277

47. Mackinnon AC, Tretiakova M, Henderson L, Mehta RG, Yan BC, Joseph L, Krausz T, Husain AN, Reid ME, Salgia R. Paxillin expression and amplification in early lung lesions of high-risk patients, lung adenocarcinoma and metastatic disease. J Clin Pathol. 2011;64:16-24.

48. Wu DW, Cheng YW, Wang J, Chen CY, Lee H. Paxillin predicts survival and relapse in non-small cell lung cancer by microRNA-218 targeting. Cancer Res. 2010;70:10392-401.

49. Justus CR, Yang LV. GPR4 decreases B16F10 melanoma cell spreading and regulates focal adhesion dynamics through the G13/Rho signaling pathway. Exp Cell Res. 2015:334:100-13.

50. Parsons JT. Focal adhesion kinase: the first 10 years. J Cell Sci. 2003;116:1409-16.

51. Muppidi JR, Schmitz R, Green JA, Xiao W, Larsen AB, Braun SE, An J, Xu $Y$, Rosenwald A, Ott G, et al. Loss of signalling via Galpha13 in germinal centre B-cell-derived lymphoma. Nature. 2014;516:254-8.

52. Healy JA, Nugent A, Rempel RE, Moffitt AB, Davis NS, Jiang X, Shingleton JR, Zhang J, Love C, Datta J, et al. GNA13 loss in germinal center B cells leads to impaired apoptosis and promotes lymphoma in vivo. Blood. 2016;127:2723-31.

53. O'Hayre M, Inoue A, Kufareva I, Wang Z, Mikelis CM, Drummond RA, Avino S, Finkel K, Kalim KW, DiPasquale G, et al. Inactivating mutations in GNA13 and RHOA in Burkitt/'s lymphoma and diffuse large B-cell lymphoma: a tumor suppressor function for the G[alpha]13/RhoA axis in B cells. Oncogene. 2016;35:3771-80.

54. Sin WC, Zhang Y, Zhong W, Adhikarakunnathu S, Powers S, Hoey T, An S, Yang J. G protein-coupled receptors GPR4 and TDAG8 are oncogenic and overexpressed in human cancers. Oncogene. 2004;23:6299-303.

55. Ihara Y, Kihara Y, Hamano F, Yanagida K, Morishita Y, Kunita A, Yamori T, Fukayama M, Aburatani H, Shimizu T, Ishii S. The G protein-coupled receptor T-cell death-associated gene 8 (TDAG8) facilitates tumor development by serving as an extracellular pH sensor. Proc Natl Acad Sci USA. 2010:107:17309-14.
56. Rosko AE, McColl KS, Zhong F, Ryder CB, Chang M-J, Sattar A, Caimi PF, Hill BT, Al-Harbi S, Almasan A, Distelhorst CW. Acidosis sensing receptor GPR65 correlates with anti-apoptotic Bcl-2 family member expression in CLL cells: potential Implications for the CLL microenvironment. J Leuk (Los Angeles, Calif). 2014;2:160.

57. Tosa N, Murakami M, Jia WY, Yokoyama M, Masunaga T, I wabuchi C, Inobe M, Iwabuchi K, Miyazaki T, Onoe K, et al. Critical function of T cell deathassociated gene 8 in glucocorticoid-induced thymocyte apoptosis. Int Immunol. 2003;15:741-9.

58. Xu N, Voyno-Yasenetskaya T, Gutkind JS. Potent transforming activity of the G13 alpha subunit defines a novel family of oncogenes. Biochem Biophys Res Commun. 1994;201:603-9.

59. Kelly P, Moeller BJ, Juneja J, Booden MA, Der CJ, Daaka Y, Dewhirst MW, Fields TA, Casey PJ. The G12 family of heterotrimeric G proteins promotes breast cancer invasion and metastasis. Proc Natl Acad Sci USA. 2006:103:8173-8.

60. Konstantinidou G, Ramadori G, Torti F, Kangasniemi K, Ramirez RE, Cai Y, Behrens C, Dellinger MT, Brekken RA, Wistuba II, et al. RHOA-FAK is a required signaling axis for the maintenance of KRAS-driven lung adenocarcinomas. Cancer Discov. 2013:3:444-57.

61. Zandvakili I, Lin Y, Morris JC, Zheng Y. Rho GTPases: anti- or pro-neoplastic targets? Oncogene. 2017;36:3213-22.

62. Sun L, Hui AM, Su Q, Vortmeyer A, Kotliarov Y, Pastorino S, Passaniti A, Menon J, Walling J, Bailey R, et al. Neuronal and glioma-derived stem cell factor induces angiogenesis within the brain. Cancer Cell. 2006:9:287-300.

63. Ginos MA, Page GP, Michalowicz BS, Patel KJ, Volker SE, Pambuccian SE, Ondrey FG, Adams GL, Gaffney PM. Identification of a gene expression signature associated with recurrent disease in squamous cell carcinoma of the head and neck. Cancer Res. 2004;64:55-63.

64. Hou J, Aerts J, den Hamer B, van ljcken W, den Bakker M, Riegman P, van der Leest C, van der Spek P, Foekens JA, Hoogsteden HC, et al. Gene expression-based classification of non-small cell lung carcinomas and survival prediction. PLOS ONE. 2010;5:e10312.

65. Selamat SA, Chung BS, Girard L, Zhang W, Zhang Y, Campan M, Siegmund KD, Koss MN, Hagen JA, Lam WL, et al. Genome-scale analysis of DNA methylation in lung adenocarcinoma and integration with mRNA expression. Genome Res. 2012;22:1197-211.

66. Garber ME, Troyanskaya OG, Schluens K, Petersen S, Thaesler Z, PacynaGengelbach M, van de Rijn M, Rosen GD, Perou CM, Whyte Rl, et al. Diversity of gene expression in adenocarcinoma of the lung. Proc Natl Acad Sci USA. 2001;98:13784-9.

67. Jones J, Otu H, Spentzos D, Kolia S, Inan M, Beecken WD, Fellbaum C, Gu X, Joseph M, Pantuck AJ, et al. Gene signatures of progression and metastasis in renal cell cancer. Clin Cancer Res. 2005;11:5730-9.

68. Beroukhim R, Brunet JP, Di Napoli A, Mertz KD, Seeley A, Pires MM, Linhart D, Worrell RA, Moch H, Rubin MA, et al. Patterns of gene expression and copy-number alterations in von-hippel lindau disease-associated and sporadic clear cell carcinoma of the kidney. Cancer Res. 2009;69:4674-81.

69. Gumz ML, Zou H, Kreinest PA, Childs AC, Belmonte LS, LeGrand SN, Wu KJ, Luxon BA, Sinha M, Parker AS, et al. Secreted frizzled-related protein 1 loss contributes to tumor phenotype of clear cell renal cell carcinoma. Clin Cancer Res. 2007;13:4740-9.

70. Radu CG, Cheng D, Nijagal A, Riedinger M, McLaughlin J, Yang LV, Johnson J, Witte ON. Normal immune development and glucocorticoidinduced thymocyte apoptosis in mice deficient for the T-cell deathassociated gene 8 receptor. Mol Cell Biol. 2006;26:668-77.

71. Tsurumaki H, Mogi C, Aoki-Saito H, Tobo M, Kamide Y, Yatomi M, Sato K, Dobashi K, Ishizuka T, Hisada T, et al. Protective role of proton-sensing TDAG8 in lipopolysaccharide-induced acute lung injury. Int J Mol Sci. 2015;16:28931-42. 